\title{
Peers Engaging in Empowering Research (PEER): Finding Women's
} Voices after Prison

\author{
Barbara J. Pickering*, Jennifer Sputek and Gayle Rutherford \\ University of Calgary, Calgary, Alberta, Canada
}

\section{Abstract}

Background: Over a period of 18 months a group of previously incarcerated women, academics, and students gathered once a week as co-researchers to not only explore the challenges of reentering the general community post incarceration, but to be a catalyst for change in how women are supported during this vulnerable time.

Method: For this inquiry we adopted Community Based Research (CBR) as the appropriate methodology in which to gain some understanding of the needs of women as they reenter the community. The co-researchers participated in all aspects of the research project including obtaining ethics approval, recruiting participants, conducting interviews, contributing to data analysis designed the research study, and disseminating the findings. Two of the co-researchers with a history of incarceration were hired as peer researchers to engage with other women with similar histories to gather their stories and expand our knowledge of the resources required upon re-entry into the community.

Results: The central theme arising from the study was the importance of genuine human connection for the women. They needed to connect to resources, connect to peers, connect to their culture and spirituality, and connect over time. The study also demonstrated the importance of involving the women themselves in finding solutions and the benefits of using peer researchers as key members of the research team.

Conclusion: Nurses are in a unique position to connect with the women at a time when they are vulnerable and possibly in search of solutions to the issues they face. It is our hope that by sharing our findings and our experiences that others will be motivated to work together in similar ways with those who are facing immense challenges in their lives.

\section{Publication History:}

Received: May16, 2016

Accepted: August 02, 2016

Published: August 04, 2016

Keywords:

Action Research, Peer Researchers, Post-incarceration, Resources, Women

\section{Introduction}

Community based research is grounded in the notion that there are communities and/or individuals struggling on the margins of society whose voices are unheard or ignored. One such community has coalesced around the experience of incarceration. The difficulties of reentry are well established in the literature and it is understood that women who have been to prison are rarely considered, much less heard, by the general community [1-5].In spite of the numerous challenges facing women as they transition from prison to the community, most research conducted by the academy has focused on the experience of women in prison [6]. More recently researchers have begun to explore the lived experience of women as they attempt to reenter their community [ 1-3, 7-10]. Flores and Pellico[3] provided a synthesis of qualitative research over the last ten years looking at the experience of previously incarcerated females. One of the findings that stood out was the women's desire to gain a sense of community membership and the difficulties associated with successful reintegration [3]

O'Brien [8] explored the critical factors of accomplishing transition from prison to community life. She asked 18 women how they defined success in terms of reentry. The women, who self-identified as having reintegrated back into the community, described five themes that stood as evidence of their success: (a) finding shelter; (b) obtaining employment or legal income; (c) reconstructing connections with others; (d) developing community membership; and (e) identifying consciousness and confidence in self. Interestingly, and relevant to this paper, a number of women commented on how participating in the research project raised their self-awareness and confidence. Such findings have important implications for how we choose to engage female offenders in the process of research as they navigate the transition from prison into their communities.

\section{Background: Whose Voice is Amplified?}

One of the greatest challenges to academic researchers working from an action-oriented perspective is connecting with people in communities who have vastly different experiences, backgrounds, and world-views. Although communities and academics may have common goals, the inability to connect across experience and language may have tainted many well-intentioned research projects. Researchers who practice within one of the Action Research (AR) methodologies traditionally intend to be collaborative[11], however, it is challenging to privilege the voices of the particular community when it is the academics who design, plan, conduct, and write up the results of the research (see [12] for a thorough critique). This is not to imply that this approach to research is without value, indeed,

"Corresponding Author: Barbara J. Pickering, University of Calgary, Calgary, Alberta, Canada, E-mail: bjpicker@ucalgary.ca

Citation: Pickering BJ, Sputek J, Rutherford G (2016) Peers Engaging in Empowering Research (PEER): Finding Women's Voices after Prison. Int J Nurs Clin Pract 3: 193. doi: http://dx.doi.org/10.15344/2394-4978/2016/193

Copyright: (C) 2016 Pickering et al. This is an open-access article distributed under the terms of the Creative Commons Attribution License, which permits unrestricted use, distribution, and reproduction in any medium, provided the original author and source are credited. 
there are numerous positive results that can come out of AR inquiries initiated and orchestrated by academics (for an example see [13]). It is interesting to note that a growing number of research studies are adopting a peer research approach [14-15].

Peer researchers are members of the community who have been trained and supported to participate as partners on a research team [15]. Roche et al. [15] identified three broad models of peer research: the advisory model where peer researchers are on a steering or advisory committee; the employment model where peer researchers are employed to complete research tasks such as data collection; and the partner model where peer researchers are partners or leaders in all phases of a research study. Most often, research studies include peer researchers in a mix of models and the "definition of peer research and the role of peer researchers shift according to context, community, the nature of the project, the understanding of community-based research, and over time." [15, p.4].

There are both advantages and challenges related to the use of peer researchers. Peer researchers, due to their direct knowledge of the experiences of the target population, are able reduce the power imbalances between researchers and participants. Additionally, they enhance the quality of data collected based on the trust relationships and credibility they have established with their peers [15-18]. At the same time, peer researchers benefit through their ability to contribute to positive change for their population or community, through learning about research processes firsthand, and through doing meaningful work [17]. However, because the peer researchers have direct experience with the research focus, their peer researcher role may involve 'emotional work' [16] whereby they are challenged to deal with issues and stories that may trigger memories of their own [19].

In some situations, peer researcher work may be tokenistic in that they are only used for the benefit of the academic researcher rather than for the benefit of their population [18]. Peer researchers are valued for their ability to connect with their peers through their common experiences, behaviours, and use of language. There should not be expectations of a different type of behaviour to occur when working with others outside of the peer group on the research team [16]. Greene [16] described this as the "precarious intersection of empowerment and efficiency" (p. 445). Peer researchers may also experience a change in relationship with their peers due to the need to set up more professional boundaries related to the research $[14,20]$ and they may have difficulty transitioning out of the project at its completion [19]. Academic researchers are challenged to maintain the rigour of the study at the same time as incorporating the peer researchers as valuable members of the team [18].

Peer researchers require supports based on their unique roles within a research team. Due to the demands for confidentiality, their usual support systems may not be available to them [15]. Partnered data collection [21] and debriefing discussions after data collection [15]can provide important support to peer researchers. Training sessions are fundamentally important [18] as is reciprocity in the research team relationships such that the peer researchers, the academic researchers, and the community benefit equitably[16]. We believe that adopting a peer researcher model of data collection helped to mitigate a measure of bias that can be inherent when those at the controls are scholars rather than those with lived experience.

Over a period of 18 months a group of previously incarcerated academics, and students gathered once a week to not only explore women, the challenges of reentering the general community post incarceration, but to be a catalyst for change in how women are supported during this vulnerable time. Early on it became clear that service delivery for women leaving prison was either inadequate or inaccessible. Consequently, the group decided to take action to try and improve access to resources through information. Even though the resources were available, for many women, they were an inaccessible mystery. These meetings, intended as a space from which to conduct an inquiry based on the principles of action research (AR), became a growing place for all involved.

This research project would not have been possible without the direct participation of women with experience of incarceration in all aspects of the research project including obtaining ethics approval, recruiting participants, conducting interviews, and contributing to data analysis. It was our hope that these findings would assist those with the power to make important policy and program changes in order to improve women's experiences of re-integration into the community after release from incarceration; that we can all work together to make it easier for women to stay out of the justice system; and that the work of the service providers will be more satisfying as they connect with the women through the ups and downs of reintegration. From a broader perspective, we also hoped that this valuable information would inform others in jurisdictions outside of the local context. Many of the barriers and challenges women face are common across contexts and the information gathered could be crucial to others working in the area of supporting women as they come out of prison. Additionally, we hope to add to a growing body of literature that explores and supports the notion of peer researchers in the context of community based and action research.

In this paper we will share both the experiences and the results of a community based inquiry that demonstrated how peer researchers were able to connect to others with similar experiences in order to tap into otherwise inaccessible information that ultimately led to a measure of social action and change for previously incarcerated women in one Canadian city. We will then discuss the implications for nursing practice based on these study findings and experiences.

\section{Methodology}

For this inquiry we adopted Community Based Research (CBR) as the appropriate methodology in which to gain some understanding of the needs of women as they reenter the community as well as challenge the dualism of researcher and researched. CBR belongs to a family of methodologies called Action Research (AR). As the goals of this research included a desire to create a space where women could be collaboratively involved in all stages of the research, CBR and AR presented as the most appropriate method. The study received ethics approval from the university research ethics board.

\section{Overview of action research}

At the root of all $\mathrm{AR}$ practices, including $\mathrm{CBR}$ is participant advocacy, which has the potential to circumvent the traditional paradigm based on a constructed separation between researchers and researched [22]. An AR framework provides a scaffold for participants and researchers to work toward a negotiated goal. Greenwood and Levin [23] proposed a balance of action, research, and participation links all forms of AR. Researchers who embrace an AR approach aim to alter the situation of the group, organization, or community 
involved in the research and collaboratively move it toward a more sustainable, liberating, and self-managing state. This approach offers co-researchers a powerful way to generate new knowledge while valuing participation to influence participants' life situations. This value reinforces a strong commitment to "democratizing the knowledge generation process" [23, p.7], such that all participants share a responsibility in the research process.

Reason [24] referred to AR as a "radically participative form of inquiry" (p. 207) that engages people in examining their own knowledge (understandings, skills, and values), and how they interpret themselves and their actions in the world [25]. Essential to the practice of $\mathrm{AR}$, participating in the research process goes beyond the dichotomous activities of collecting/analyzing data or simply providing data; it entails entering into the relational space of democratizing knowledge [22-23]. Democratizing knowledge means that knowledge holders not only participate equally in the process, but also have a say in what counts as knowledge.

Although proponents of different AR approaches call for different levels of participation, they all share a participatory worldview [22]. Taking up a participatory paradigm involves relating with participants in ways based on reciprocity, and offers ways to challenge the traditional empiricism of positivist science that claims to place the researcher in a value-neutral position of observation [26]. From an AR perspective, the typical researcher/participant dichotomy with inherent power differentials and differing values or goals is mitigated. Consequently, the research relational processes proceed from a participative and collaborative perspective.

\section{Method}

True to the principles of AR and CBR, women with a history of incarceration were directly involved in three different capacities throughout the inquiry: 1) as members of a co-researcher group who provided input and contributed to decision-making related to the research methodology, findings, and recommendations for change; 2) as hired peer researchers who work along with academic researchers in engaging with participants and collecting research data; and 3) as participants who are and have cycled in and out of incarceration. A total of seven co-researchers participated in at least one of the meetings, with a core of five co-researchers participating throughout most of the study. The co-researchers received honoraria each meeting along with transit tickets and money for child-care when required. All of the co-researchers signed an informed consent that outlined the confidentiality required as well as the risks and benefits related to their participation in the study.

Two of these women were hired as peer researchers following the processes recommended by the Ontario Women's Health Network[27] and were paid an hourly wage. The peer researchers joined the principal investigator (GR) at a research ethics board meeting and assisted in explaining the research processes to the members of the board. They worked as partners in interviewing the women with a history of incarceration and along with the principal investigator in interviewing the service providers. The peer researchers were provided a dedicated cell phone each and used a specific email address so that participants could be in touch with them without providing their personal contact information. One of the peer researchers assisted with the use of NVivo in data analysis. All of the co-researchers were invited to participate in dissemination of the findings and at least five of them did so. Thus, we had elements of all three types of peer researcher models; the advisory, the employment, and the partner; in our study.

The initial intent was to interview women prior to release from the several different facilities however, barriers including time restraints, ethics approval, and funding resulted in all of our interviews being conducted post-release. Peer researchers conducted 20 interviews with 11 women who experienced incarceration; including repeated interviews with five women who had been released within the past two weeks and single interviews with six women who had a longer post-release time. Women were asked about their incarceration history, what they had done to re-integrate back into society, about the services they had accessed or needed to access for help with their transition after release, along with the most important message they had for those who were working toward change. Of the 11 women, three were Aboriginal with an overall age range from 31 to 54 . The number of incarceration experiences ranged from zero (one woman) to three for federal time, from zero to 15 for provincial time, and from 1 to "too many to count" (at least 4 women) for Remand time. Three of the women reported involvement with the justice system as a young offender. In addition, we interviewed 10 front-line service providers to get their perspectives on gaps in services for women leaving incarceration. Interviews were conducted between July 2011 and February 2012.

All of the interviews were tape recorded with the participant's consent. One of the co- researchers with relevant past experience transcribed these recordings, receiving transcriptionist payment for her skills. Two of the authors (JS \& GR) each used NVivo 9 to sort the data into themes. These themes were then brought back to the other co-researchers at the weekly meetings for further discussion and validation of the trustworthiness of the data. The findings of the Action Research project come both through the process of the research and the data collected through interviews. The findings demonstrate the experiences and perceptions of the interviewees and may or may not reflect full knowledge of the systems involved.

\section{Results}

The major theme that ties all of the data together is Human Connection. Both the women who have experienced incarceration and the service providers who work with them expressed a desire to build connections based on mutual trust and respect. Service providers reported that at times the women could be abrasive and not entirely truthful and the service providers could be sworn at and "exposed to a little bit of abuse ... from the client". The women may not always follow through on negotiated plans, leading to some frustration on the part of the service providers. However, the service providers acknowledged that it takes time for the women to learn new skills,replacing the ones they used in order to survive on the streets and in prison. "Listening to the stories of these ladies [helps us understand] that they really are as special as anybody else. Whether they committed from bus tickets to first-degree murder. It doesn't matter. They deserve help. They deserve respect" (Service Provider). Building a positive relationship between the women and service providers also takes time and patience as the women work through the steps required to recover and learn new skills. The women fundamentally want to be "taken at face value and not pre-judged". Our research findings indicated that one of the most important factors that leads to successful re-entry is to have someone who believes in them offering support through the ups and downs of recovery. 


\section{Connecting with resources}

Both the service providers and women interviewees reported a lack of programs and a lack of knowledge about the programs that are available. The lack of available resources was particularly true in the areas of affordable and stable housing and accessible, long-term addiction treatment and trauma counselling. Other findings included the acknowledgement that resources are frequently changing and it is difficult for both the women and the service providers to know what is available and who is eligible for each service. One of the women said, "If I had known that there were services like this before, who knows, I would maybe never have even ended up in prison". One service provider noted that she never knew there were so many programs available until she attended an event that brought both service providers and post incarcerated women together.

Women reported that they may not access programs because they do not feel that they deserve the help, "oh, I'm a junkie, I don't deserve this". The women needed to know that they were eligible for the programs; needed help navigating through the systems of services, and needed advocates who could help them to find and get all that they needed to reintegrate into the community. "It's overwhelming for anyone to go through bureaucracy and systems and so if you are a woman who has low self-esteem or hasn't ever been helped in the past, it's going to be ugly and hard" (Service Provider). At the same time, the women needed to feel it was their choice (outside of parole or probation requirements) to access the available programs when they were ready. As one service provider said, "We have to tell them that we are not here to solve your problem, we're not here to give you the thing that you need or want, we are here to give you the choices and options, and give you the moral support that you can make it."

The data indicated that it is difficult to navigate through the eligibility criteria for each of the programs, making it challenging to identify gaps in services. For instance, one housing program was available that met the needs of those who have been incarcerated and those who have a diagnosed mental illness. However, there were many women who do not fit these specific criteria yet had similar need for housing with on-going support. In particular, single women who do not have custody of their children were challenged to find affordable and secure housing.

Jurisdictional issues need to be coordinated such that women who are in the federal system are eligible to apply for provincial services. One example is the inability to access medical benefits or apply for financial support through a provincial employment program while still living under federal jurisdiction after release. Another example is the inability to apply for social services or addictions treatment prior to release, particularly if the woman is moving to a different city after release.

There is significant need for more addiction treatment programs that are longer term and more accessible to women immediately upon release from prison or jail. Some of the women indicated that they left incarceration with a goal of overcoming their addictions. However, if there is a waiting period after release, and if one of the requirements is a specific period of sobriety before entering the program, they were likely to fail, particularly if they did not have access to safe housing away from their past addiction related activities. One service provider even reported that some women will even use drugs in order to be eligible to use a detox program to get safely off the street. According to this service provider participant, "It's a system that perpetuates itself".
Transitional housing was one of the key requirements for women leaving incarceration, whether federal, provincial, or remands custody in order to stop the cycling in and out of prison. Women required housing that included on-going programming and support as they reintegrated into the community. What is needed is housing that can provide a secure and safe place for the length of time each woman needs and that is not based on artificial time restrictions.

Women spoke about challenges they face due to their addictions and aspects of their mental health. One woman in particular expressed concern that she was being prescribed too many medications, "and you get put on all kinds of meds and pretty soon you're gonna be a mental patient when you weren't one before...but in my opinion, I don't need an anti-depressant,...I am depressed because my life is in rough shape." Women needed on-going access to counselling and support related to their past histories of trauma and abuse in order to overcome their addictions and to move forward with their lives. Service providers identified a need for more mental health training, for both diagnosed and undiagnosed mental health issues and more "trauma stage training". Clearly there is much to be learned from women who have a great deal to say about what is best for them.

Connecting to resources also meant finding meaningful employment. One woman put it this way:

So it's not that a person doesn't try. You can work your buns off, and then when you start getting all that rejection it starts to get awfully hard on your self-esteem, so then you almost don't want to - it puts me in a place I don't want to even apply anymore because it's almost easier if - well if I don't apply I can't get rejected, right?

Women need job training skills, including workplace mentality skills. In other words they need to learn how to function appropriately in a new and unfamiliar environment after spending time on the street and in prison. They also want employment that builds on their strengths and past work experience. They need to know how to deal with their past criminal records, as one woman explained:

People that have been incarcerated don't necessarily hide from their crime because they are ashamed - they have to live two separate lives because society is not accepting and/or forgiving - so it's not by choice. They will hide their past to keep their jobs, which is their means of survival and not because they are ashamed. Heck I already lost one job due to the fact they found out about my record.

It was suggested that programs and services need to be linked, building partnerships so that women can access multiple services at one place. Each agency providing services to women leaving incarceration could be linked to other agencies through liaison persons, someone to whom service providers could refer clients or ask questions about services.

\section{Connecting with Peers}

One of the biggest challenges facing women who are trying to stop cycling in and out of prison was the need to disconnect from those with whom they previously associated on the streets and through their addictions. Being around others who talk about drugs and "the lifestyle" is dangerous, because then "I will get tied up into it". The women who tend to do better are those with social support, when they have positive family or friends in their 
lives. Lack of social support, boredom, and loneliness can often result in relapse. One woman said, "That was the problem the last time, I had no friends and seriously, I just wanted to go back to jail so I could visit some of my friends because I had no friends out there".

One of the key findings of our work together in the AR project is the importance of peer support. One of the women spoke about the meaning of attending the weekly project meetings, "Going to [our group meetings] gave me a sense of belonging, responsibility, a priority. It's given me support. I've had to become stronger in order to be strong for other people, you know. It's given me the opportunity to tell my story. It's been great". Women can help each other to navigate the systems, sharing what they have learned, "What has helped me is the other women. I learned more from them and where to go than I did from any service provider". One of the recommendations arising from this research was the development of a formal peer support program for women leaving incarceration.

Connection with peers can provide some stability in the women's lives and help them rebuild their dignity. Having the ability to talk with other women who have also experienced incarceration is powerful, "Hearing other people and talking to other people, it's like, wow, I'm not the only one and I'm not a bad person". Women can hold each other accountable and understand the ups and downs of recovery and reintegration. In particular, meeting with women who have been successful in their transition out of incarceration would be helpful, "just to have that validation to know that I wasn't alone and that somebody else had gone through it and made it through it and was O.K." Being with other women with similar experiences lets women "let their guard down" and to be truly honest and open about who they are and what they have experienced without judgement or shame. The laughter, the anger, and the tears are genuine, necessary, and shared. Peers are the ones women will call in times of need because they know they will be truly heard, understood, and supported.

\section{Connecting through culture and spirituality}

One of the significant aspects of some of the women's road to recovery was to reconnect with their culture and their spirituality. One of the women spoke about the difficulty she had when she tried to find help and she "accessed the wrong ones that didn't fit" for her. She felt there was a cultural clash because they wouldn't allow her to smudge. She then went to a healing lodge where she benefited greatly from the cultural connections. She said, "My cultural and my spiritual is huge in my life. And that's I think what is keeping me where I am right now". Another woman spoke about how when she reads her Bible or smudges, she is more likely to stay on the path to her recovery. According to her, speaking with an Elder has a powerful influence on her life.

\section{Connecting over Time}

Women need support and services over a long period of time, prior to their involvement with the justice system, during their incarceration including pre-release planning, and for a significant amount of time after release. As suggested in the section Connection with Resources, support needed to begin prior to release. According to both service providers and some of the women, setting goals and making a realistic release plan in collaboration with community agencies prior to release leads to greater chances of success.One example of suggested prerelease planning was that women could leave prison with their I. D. intact and with completed medical examinations if required for addictions treatment.
Of major concern was the loss of services at warrant expiry date (WED), or on statutory release from the federal system when they have no residency requirement and thus no transitional housing. At this point, the women were no longer eligible to stay in a halfway house or to access counselling through CSC. As one service provider said, after they have worked with a woman to help her start to deal with a painful past, "and you're giving that person hope and then... oh I'm sorry it's warrant expiry date, you can't access our services any more. So where is that person going to go?" One woman spoke about how devastated she was that she was kept inside until her WED, even though her request to have the support of a parole officer after her release was denied. Another woman said, "Just because I am done, don't just drop me" knowing that the extra need for accountability was crucial to her successful re-entry.

Women needed somewhere to obtain services and support when they had "fallen down", somewhere they could receive support to pick themselves up again and continue their journey forward. One woman said that she would really like to have somewhere to go where someone would say, "Hey, you know, 'do you wanna talk?'“ rather than sending her to other services. She suggested that this be "someone that's normal, that didn't do drugs, to give you the reminder that there's a better life than that."

The data spoke to the fact that each person was unique and needed different programs and services at various times. Some were able to access the services fairly independently and others needed someone to accompany them and possibly help to advocate for them when accessing other services. As one woman said, "They need to open their mandates. They need to know not everybody fits in their boxes ... you can't put a time line or a mandate on somebody's life".

One service provider suggested that agencies are trying to get the women "on their feet as fast as possible", including housing, resumes, education, employment etc. She believed that this was too much, too fast, "You have to have all your eggs lined up and then we expect you to maintain this in the community with no supports". One of the women said that people, such as herself, who are going through recovery "need time to do that [recovery] number one before spending all of their time worrying about getting a job ... because I can get a job with a giant pay check and spend that on crack and end up back in jail, no problem, right?" She wanted time to be in the community and in recovery before being pressured to get a job. Another woman said, "if I take on too much at once I think it is going to overwhelm me". Women needed to learn a wide variety of skills from how to think, to how to dress, to new job skills, "To put it plainly, because you can go to any programming and stuff but 45 days [participating in a program] out of 20 years [of involvement with the justice system] really isn't going to do it."

\section{On peer researchers}

One of the two peer researchers (JS) reflected on her experience as she wrote this section. She included some meaningful quotes that supported the positive role she had as she engaged the women in conversations about their experiences.

As a peer researcher you wear a multitude of different hats and play a mixture of different roles under that peer support umbrella. You have to be open, but reserved, and you have to be professional and yet personal. You have to keep in the back of your mind at all times that 
you are not there to 'fix' the other person. You are there to support but not to take on the other person's problems. You are there to give them a hand up not to build a house for them. We understood that there were boundaries and that is why we had dedicated cell phones and email address so we did not use personal contact information.

A peer researcher is much more than a data collector. We did more than interview the women; we tried to connect them to resources. One of the things we did with the group of co-researcher was to create a resource manual of agencies that provide services to women leaving incarceration. This allowed for better peer researcher knowledge of resources, which gave us confidence to help them to find the resources they needed.

There are challenges and advantages to being a peer researcher. One of the challenges is that you are still struggling with some of the issues that you are supporting others through, and seeking resources yourself as well. If you didn't have luck on your journey it may be a challenge to help others to find that help. But by taking a step back and looking at it from a broader perspective, it might help both you and the other person. Not everyone is able to be a peer researcher, the person has to have some stability in their life in order to be successful in that role. In my case, my children were my anchor that allowed me to be grounded a bit more - my centre.

One of the biggest advantages is for the person on the receiving end is that they are talking with someone who has been there, has touched it, felt it, and experienced it. We have the credibility because we have lived in the trenches and even though we haven't been long out of the trenches, we can offer hope that they can move on. The peer researcher is able to give back and one of the best ways to help yourself and to build yourself up is to help other women. One of the women interviewed said, "The fact that there is an ex-parolee willing to open herself up to me, to accept me for everything that I am, totally. I have never been able to utilize a lot of the services because it's always people who never understood me....I wouldn't be nervous to approach you guys because you're the same as me or you were and you are going to show me how to be the same as you. There is nothing intimidating about it" (Peer interview \#1). As a peer researcher, it is amazing even to see the little successes of others - like finishing parole or being successful get into housing, or have a successful visit with your child. To be able to say that you had a part in helping the other person achieve that gives yourself back some of your self-worth.

Another advantage of peer researchers is that you take 'judgement' off the table. When I interviewed someone else who has been in jail, there were no assumptions or judgements because I had been there myself. On the flip side, when you are 'out there' about being an excon, even though I am doing all these good things, I am still under the convict umbrella for the service providers and for society in general.

What made me effective as a peer researcher was what made me less effective in larger research meetings where I was seen as 'crass' or disrespectful when I 'told it like it was'. With the larger research meetings, I felt that 'tokenism' was more present. However, in a service provider interview it was clear that the peer researcher offered value, "I mean, you guys have een there, right, so I mean you have a different frame of mind, which I mean, you've been through the same kind of crisis and problems and everything else" (Service Provider Interview \#2).

In our own research meetings with co-researchers I felt that the power was more in our corner because we had the experience. We all came to that circle as equals, as women. Everyone brought something different to the table-the academics knew how to do the research and we knew how to reach out and connect as women. It was organic. By meeting together as women we were able to develop our plan. We decided on the questions and how we were doing to do the research. I knew I was important as a peer researcher because I knew that my peers would tell me things they would not tell others. We used the 'power' in a positive way, we knew what we were doing was important, and we were 'empowered'. I really wanted to get the right set of answers for the research.

One of the things we may have done better was to have better supports for the peer researchers. We had access to a psychologist from the parole office if we needed extra emotional support outside of the group. However, there were barriers because the psychologist was under the parole umbrella. This was expressed well by one of the peer interviewees (\#5) when she talked about her belief about counselling, "Cause there was a lot of times that I needed someone or you know what I mean or would have talked to someone. But even the mandated weekly psychology appointments, she was writing reports to parole". An independent psychologist may have been a better choice. Most of the debriefing happened at our weekly meetings, we ate together, and talked through anything emotional that came up during the interviews and how we were feeling.

\section{Discussion}

Echoing the extant literature, this inquiry found numerous ways in which the stories of women attempting to integrate into the community are similar. For example, it can be argued with a measure of certainty that the most pressing needs for women leaving prison include housing, finding meaningful employment, re-establishing ties with their families or communities, and addressing mental health concerns such as substance use and addiction $[2-3,28]$. We found that both women and service providers agreed that first things first (i.e., basic needs) are fundamental to gaining some sort of traction on the outside.

However, the nuances of how needs are established, prioritized, and met is still an area of ongoing discussion to which these results contribute. For example, a key finding was the need for the unification of services in terms of awareness, accessibility, and cross agency cooperation. It was acknowledged that there were resources but many of the women were unaware of them or weren't able to access the various programs for a number of reasons. The women felt this was such an important concern that to address this lack of general knowledge they developed a comprehensive resource guide that can be used by service providers and women when leaving prison or remand.

\section{Making Our Way Home}

This study adds to the growing evidence that the most influential strategies for successful re-entry are enacted through connected relationships [29-31]. Developing strong relationships with service providers such as parole officers and counsellors, community and family members, as well as positive peers is both fruitful and protective [29,32]. Important relationships were developed between service providers and the women through listening and recognizing that they deserve help and respect irrespective of their crime. Cobbina 
[29] noted that research supports the notion that quality relationships between former female inmates and their supervising officers can impact not only the re-entry process, but also criminal outcomes.

Pro-social peer relationships were key as well where women who share similar stories can help each other to move forward. Covington [30] viewed these important relationships through Relational Cultural Theory, developed by Jean Baker Miller [31], that posited women (and others) achieve well-being through growth fostering relationships $[31,33]$. The women and service providers who shared their views of what is most helpful for women as they re-enter the community concurred. The data suggested that from these growth-fostering relationships all other connections emerged.

For example, the data concerning connecting to resources supports other findings (see [13]) that suggest formerly incarcerated women struggle with locating and navigating the tangles of information that not only overwhelms, but sometimes de-rails women as they attempt to re-engage in community life. In this study, the women often spoke of being overwhelmed and sometimes feeling like the safest place would be with their peers back in prison. Having engaging and empowering relationships with service providers as well as parole officers helped to mitigate the difficulties and risks that came with stepping into a free life $[13,34]$. Patience and compassion were key ingredients found in the connected relationships among the women and between the women and the service providers.

Another point of connection concerned the dimension of spirituality. As there are relatively few studies [35-37] that focus on, or acknowledge the role of spirituality in the re-entry process the data in this research adds to a sparse literature. Some of the women found that this connection was key as they drew from their spiritual and cultural connections for added support. Therapeutic connections can also take the form of informal or formal mental health counselling. In a systematic review meant to help nurses address the mental health needs of women as they exit prison, Stanton [38] noted that the quality of the professional relationship with exiting women was a significant factor in how they managed to successfully address mental health concerns. Additionally, in an action research project conducted with the same group of women that participated in this study, one of the key findings in terms of mental health services were messages to counsellors that "I don't need a fix" and "there is a big difference between our definition of trauma and service providers' definition of trauma; to us trauma is 'shit happens"' [35, p.279]. It is clear that helping professionals have a lot to learn from women with lived experienced of incarceration.

\section{On Peer Researchers}

The experiences described by the peer researcher in our study were similar to those previously described in the background literature. They were fundamentally important to the research project due to their intimate knowledge of the experience of being incarcerated and their ability to connect with their peers, both with their co-researchers and the women who were interviewed for the study $[15,16,18]$. They also faced challenges such as dealing with the same issues as those they interviewed [19], balancing their identity as a researcher with that of a peer[20], and feeling that different behavior was expected of them when working with professionals outside of the research group [16]. Support and debriefing was essential for the peer researchers [15] and in this study, the peer researchers depended mostly on their co-researcher for this rather than turning to an assigned professional for support.
It is clear from the peer researcher's reflections that she benefited from her role, in particular through the development of peer support among the co-researchers and from her ability to make a difference to other women. This is similar to the findings of Heidemann, Cederbaum, Martinez, and LeBel[39] in a mixed method study with formerly incarcerated women where they found that helping other women was positively associated with self-esteem and social support when other variables were held constant. The women in the Heidemann et al. [39] study felt good about their ability to contribute positively to the community and despite feeling socially excluded by others in society, they felt better about themselves. Similarly, the peer researchers in this study were positive about their contributions to the study and to their peers.

\section{Study Limitations and Further Research}

As in all qualitative studies, our data reflects the findings from a small sample from one city in Western Canada. Although the findings are similar to the extant literature, the findings from this study may not be representative of all settings and all women experiencing reentry after incarceration. Another limitation is that we have the voice of only one of the two peer researchers in this paper, the addition of the voice of the second peer researcher may have led to the addition of a somewhat different perspective. However, one of the strengths of this study was the inclusion of the perspective of service providers along with the women.

Additional research in another community with another group of women using this methodology would empower and engage even more women in terms of having an effect on their own experience, their peers, and those who are in a professional position to help and support. Consideration of employing this methodology with service providers as co-researchers and peers would address an important gap in the literature. It was clear from this study that service providers experience their own forms of distress when trying to support women in these difficult circumstances.

\section{Implications for Nursing}

Nurses come into contact with women who have previously been incarcerated in hospital and community settings, whether or not they are aware, and should be prepared to meet the unique needs of this group of women[3,40]. Therefore, it is important for nurses to gain insight into the lives of the women and the challenges they encounter after incarceration [3].

As they are often in early contact in terms of health care, nurses are in a unique position to connect with the women at a time when they are vulnerable and possibly in search of solutions to the issues they face [41].

A little extra warmth and kindness could make all the difference in encouraging a woman's successful journey on a new path; conversely, a frustrated and judgmental tone could be the trigger that nudges her back into the vicious, harmful cycle from which she was newly released [40, p.175].

Nurses can provide support, education, and care based on their ability to build trusting relationships and to recognize the unique needs of each woman [42]. They should use their assessment skills to review the mental health history of the women, including anxiety, 
Citation: Pickering BJ, Sputek J, Rutherford G (2016) Peers Engaging in Empowering Research (PEER): Finding Women's Voices after Prison. Int J Nurs Clin Pract 3: 193. doi: http://dx.doi.org/10.15344/2394-4978/2016/193

Page 7 of 8

depression, Post-Traumatic Stress Disorder, and addictions, and connect them with appropriate resources $[3,38]$. Nurses have the ability to provide case management support based on the goals established in partnership with each of the women [42]. They should also advocate for system-wide changes to reduce the health disparities experienced by the women [3].

Most importantly, nursing professionals can support women who have been in prison to work together to overcome their challenges. Stanton et al. [38] suggested that community-based research "may be especially beneficial by empowering released women and promoting the translation of research findings into practice" (p. 329). It is our hope that by sharing our findings and our experiences that others will be motivated to work together in similar ways with those who are facing immense challenges in their lives.

\section{Conclusion}

Our aims in this paper were twofold. First we wanted to share the results that arose from this inquiry and offer them as viable considerations for supporting women as they exit prison and enter the general community. These results are relevant not only for the knowledge that has been shared but also for how it was gathered. Our second aimwas to add to the literature supporting the practice of $\mathrm{AR}$ in the form of Community Based Research while engaging peer researchers as part of the process. Although AR is no longer in its infancy it is still a developing methodology and we believe that all practitioners have valuable experiences that could help inform others adopting this type of methodology.

We believe that the peer researchers gave access to depth of knowledge that would otherwise be unavailable to academic researchers. As co-researchers with women with the lived experience of incarceration, we were privileged to share a depth of experience that was life-changing for all of us. We experienced a depth of authentic human connection that engaged and empowered all of us. As in all connected relationships we had ups and downs, joys and challenges, all of which contributed to our growth as a group. Within the group the women played a central collaborative role, one that brought them together in unique way, that met an unrealized need for connection. Our work together led to unique insights that required all of our experiences and expertise. The following quote from one of the coresearchers acknowledges the fundamental importance of involving the women in their journey forward.

I think I have said from day one I mean we need to have women that have gone through what we have gone through to help us move forward. Um, I don't think those that are just sitting looking at a textbook are in any position to help other than to analyze your brain. I think putting some key people that have gone through the system and know what these women are going through when they come out is key. And it's a matter of, and I have said it before, it's a matter of helping good women help themselves. It's not a matter of supporting these women. It's a matter of truly helping them so they can get passed this and have a life outside of incarceration. (Interview \#3)

All authors of this paper were directly involved in the weekly coresearcher meetings. At the time of the study, Barbara Pickering was a Masters of Counselling Psychology student, Jen Sputek was a peer researcher, and Gayle Rutherford was Principal Investigator. Jen Sputek and Gayle Rutherford were involved in the design of the study, acquisition of data, analysis and interpretation of the data. Barbara Pickering was involved in the analysis and interpretation of the data. All authors were involved in drafting the manuscript and gave final approval to the submitted manuscript.

\section{Conflict of Interest}

The authors have no conflict of interest to disclose.

\section{Funding}

This study was supported through a University Research Grant Committee fund.

\section{References}

1. Dodge M, Pogrebin MR (2001) Collateral costs of imprisonment for women: Complications of reintegration. The Prison Journal 81: 42-54.

2. Evans $L$ (2007) Locked up, then locked out. Women and Therapy 29: 285308.

3. Flores JA, Pellico LH (2011)A meta-synthesis of women's postincarceration experience. J Obstet Gynecol Neonatal Nurs 40: 486-496.

4. Opsal TD (2011) Women disrupting a marginalized identity: Subverting the parolee identity through narrative. Journal of Contemporary Ethnography 40: $135-167$

5. Opsal TD (2012) 'Livin'on the Straights': Identity, desistance, and work among women post-Incarceration. Sociological Inquiry 82: 378-403.

6. Mclean RL, Robarge J, Sherman SG (2006) Release from jail: Moment of crisis or window of opportunity for female detainees? Journal of Urban Health: Bulletin of the New York Academy of Medicine 83: 382-393.

7. Harm NJ, Phillips SD (2001) You can't go home again: Women and criminal recidivism. Journal of Offender Rehabilitation 32: 3-21.

8. O'Brien P (2001a) “Just like baking a cake”: Women describe the necessary ingredients for successful re-entry after incarceration. Families in Society 82: $287-295$

9. O'Brien $\mathrm{P}(2001 \mathrm{~b})$ Making it in the "free world": Women in transition from prison. Albany, NY: State University of New York Press. $212 \mathrm{p}$

10. Ritchie BE (2001) Challenges incarcerated women face as they return to their communities: Findings from life history interviews. Crime and Delinquency 47: 368-389.

11. Wicks PG, Reason $P$ (2009) Initiating action research: Challenges and paradoxes of opening communicative space. Action Research 7: 243-262.

12. Greenwood DJ (2002) Action research: Unfulfilled promises and unme challenges. Concepts and transformation 7: 117-139.

13. Ireland C (2007) Parolee day treatment in California: action research with parolees in an urban setting. Justice Policy Journal 4: 1-35.

14. Guta A, Flicker S, Roche B (2013) Governing through community allegiance: A qualitative examination of peer research in community-based participatory research. Critical Public Health 23: 432-451.

15. Roche B, Guta A, Flicker S (2010) Peer research I: Models of practice. Toronto: Wellesley Institute.

16. Greene S (2013) Peer research assistantships and the ethics of reciprocity in community-based research. Journal of Empirical Research on Human Research Ethics 8: 141-152.

17. Logie C, James L, Tharao W, Loutfy M (2012) Opportunities, ethica challenges, and lessons learned from working with peer research assistants in a multi-method HIV Community-Based Research Study in Ontario, Canada. Journal of Empirical Research on Human Research Ethics: An International Journal 7: 10-19.

18. Lushley C, Munro E (2015) Participatory peer research methodology: An effective method for obtaining young people's perspectives on transitions from care to adulthood? Qualitative Social Work 14: 522-537. 
Citation: Pickering BJ, Sputek J, Rutherford G (2016) Peers Engaging in Empowering Research (PEER): Finding Women's Voices after Prison. Int J Nurs Clin Pract 3: 193. doi: http://dx.doi.org/10.15344/2394-4978/2016/193

19. Flicker S, Roche B, Guta A (2010) Peer research III: Ethical issues. Toronto: Wellesley Institute.

20. Burns S, Schubotz D (2009) Demonstrating the merits of the peer research process: A Northern Ireland case study. Field Methods, 21: 309-326.

21. Guta A, Flicker S, Roche B (2010) Peer research II: Management, support, and supervision. Toronto: Wellesley Institute.

22. Reason P, Bradbury H (2008) Introduction. In P. Reason \& H. Bradbury (Eds.) The sage handbook of action research (2nd ed.)(pp. 1-10). London, UK: Sage.

23. Greenwood DJ, Levin M (2007) Introduction to action research: Social research for social change (2nd ed.). London, UK: Sage.

24. Reason P (1999) Integrating action and reflection through co-operative inquiry. Management Learning 30: 207-225.

25. Kemmis S, Wilkinson M (1998) Participatory action research and the study of practice. In B. Atweh, S. Kemmis, \& P. Weeks (Eds.), Action research in practice: Partnerships for social justice in education. (pp. 21-36). New York, NY: Routlege.

26. Shotter $J(2003)$ The intellectual legitimacy of participatory action research Its grounding in 'the interactive moment'. Human Systems: The Journal of Systemic Consultation and Management 14: 3-22.

27. Ontario Women's Health Network (2009) Inclusion research handbook. Toronto: OWHN.

28. Parsons ML, Warner-Robbins C (2002) Factors that support women's successful transition to the community after jail/prison. Health Care Women Int 23: 6-18.

29. Cobbina JE (2010) Reintegration success and failure: Factors impacting reintegration among incarcerated and formerly incarcerated women. Journal of Offender Rehabilitation, 49: 210-232.

30. Covington SS (2007) The relational theory of women's psychological development. In R. Zaplin (Ed.), Female offenders: Critical perspectives and effective interventions (2nd ed.). Sudbury, MA: Jones and Bartlett.

31. Miller JB (2008) How change happens: Controlling images, mutuality, and power. Women and Therapy 31: 109-127.

32. Johnson IM (2015) Women Parolees' Perceptions of Parole Experiences and Parole Officers. American Journal of Criminal Justice 40: 785-810.

33. Jordan JV (2010) The power of connection: Recent developments in relational-cultural theory. London, UK: Taylor \& Francis

34. Opsal T, Foley A (2013) Making it on the Outside: Understanding Barriers to Women's Post-Incarceration Reintegration. Sociology Compass 7: 265277.

35. Schneider RZ, Feltley KM (2009) "No matter what has been done wrong can always be redone right": Spirituality in the lives of imprisoned battered women. Violence Against Women 15: 443-459.

36. Waldram JB (1993) Aboriginal spirituality: Symbolic healing in Canadian prisons Cult Med Psychiatry 1: 7 345-362.

37. Stanton A, Kako P, Sawin K (2016) Mental health issues of women after release from jail and prison: A systematic review. Issues in Mental Health Nursing 37: 299-331.

38. Heidemann G, Cederbaum J, Martinez S, LeBel T (2016) Wounded healers: How formerly incarcerated women help themselves by helping others. Punishment \& Society 19: 3-26.

39. Leitzel C, Madrazo N, Warner-Robbins C (2011) Meeting the health needs ofpostincarcerated women: Hoe Welcome Home Ministries helps bridge the gap and implications for public health professionals. Home Health Care Management \& Practice 23: 168-175.

40. Eshareturi C, Serrant-Green L, Bayliss-Pratt L, Galbraith V (2014) The case for nurses as central providers of health and social care services for ex-offenders: a discussion paper. J Adv Nurs 70: 1030-1039.

41. Colbert AM, Durand V (2016) Women in transition to health: A theory-based intervention to increase engagement in care for women recently released from jail or prison. J Forensic Nurs 12: 20-25.

This article was originally published in a special issue:

Community-Based Participatory Research Practices

Handled by Editor(s):

Dr. Alice M. Tse

Department of Nursing

University of Hawai'i at Mānoa

United States 